\title{
Synthesis and Properties of Bio-based Adhesives Derived from Plant Oil Residues
}

\author{
Xiaosheng Liu ${ }^{1}$, Huidong $\mathrm{Su}^{1}$, Yanfang Pang ${ }^{1}$, Dianji Yang ${ }^{2}$, Yongqiang Jiang ${ }^{1}$, An Mao, ", \\ Yifu Yuan ${ }^{1, *}$, Weitao $\mathrm{Xu}^{3, *}$ \\ ${ }^{1}$ Key Laboratory of State Forestry Administration for Silviculture of the lower Yellow River, College of Forestry, Shandong Agricultural \\ University, Taian, China \\ ${ }^{2}$ Dongying Shengji Environmental Protection Engineering Co., Ltd, Dongying, China \\ ${ }^{3}$ Planning and Design Institute of Forest Products Industry of National Forestry and Grassland Administration, Beiijing, China
}

\section{Email address:}

dannymaoan@126.com (An Mao), yuanyf16@163.com (Yifu Yuan),mjgbw_001@163.com (Weitao Xu)

${ }^{*}$ Corresponding author

\section{To cite this article:}

Xiaosheng Liu, Huidong Su, Yanfang Pang, Dianji Yang, Yongqiang Jiang, An Mao, Yifu Yuan, Weitao Xu. Synthesis and Properties of Bio-based Adhesives Derived from Plant Oil Residues. American Journal of Modern Energy. Vol. 5, No. 6, 2019, pp. 94-99. doi: 10.11648/j.ajme.20190506.12

Received: December 16, 2019; Accepted: December 25, 2019; Published: January 8, 2020

\begin{abstract}
Cottonseed oil residue (COR) is a by-product of cottonseed extracted by prepressing or direct solvent extraction. The protein content of COR can reach 50\% and higher, but it has not been effectively utilized. In this study, bio-based adhesives were synthesized from COR, maleic anhydride, and urea. The obtained adhesives were then analyzed by Fourier transform infrared (FTIR) and Thermogravimetric (TG), and tested as wood composite panel binders. The results indicated that the optimal synthesis conditions of the modified COR adhesive were: the urea concentration was $2 \mathrm{~mol} / \mathrm{L}$, the maleic anhydride content was $6 \%$, and the reaction temperature was $70^{\circ} \mathrm{C}$. Infrared spectrum revealed a new characteristic peak appeared at $2216 \mathrm{~cm}^{-1}$, which indicated that the protein in cottonseed reacted with maleic anhydride to form a stable structure, which improved the water resistance of the adhesive. The TG curve of maleic anhydride/urea modified COR adhesive showed that the peak value of the adhesive shifted back in the second and third stages, which indicated that the modified adhesive had better thermal stability and improved water resistance than those of unmodified ones. The study results could provide a theoretical basis and scientific guidance for the appropriate processing method and application technology development of COR.
\end{abstract}

Keywords: Bio-based Adhesive, Oil Residue, Bonding Strength, Composite Panel, Modification

\section{Introduction}

In recent years, wood panel industry is developing quickly in China. The annual production of wood composite panels in 2018 was 299 million cubic meters [1]. Urea-formaldehyde (UF) resin is one of the primary adhesives that are commonly used in producing wood panels, such as plywood, particleboard, and fiberboard. However, the panels bonded by UF resins have problems of formaldehyde emission and poor water resistance [2-4]. With the development of social economy and people's lives, the requirements for environmental friendly class of wood panel products are getting higher. To solve this problem, currently, two research directions have been proposed: one is to modify UF and other formaldehyde-based resins with special materials or agents to improve water resistance and lower the amount of formaldehyde emission $[5,6]$; the other direction is to replace formaldehyde-based resins with no formaldehyde-added adhesives to bond composite panel products [7-10].

Protein adhesive is one of the adhesives that have no formaldehyde addition and satisfied performance [11-13]. The primary protein adhesive is soybean adhesive which is usually made from soybean protein, crosslinking agents, and other additives. The soybean protein was usually modified into a high molecular polymer with crosslinking structure. Soybean protein powders could also be used as fillings or additives to lower the formaldehyde content of thermal setting adhesives and also lower the cost of the adhesives. 
Soybean meal, the main raw material of soybean protein adhesive, is the plant protein raw material with the largest consumption at present. It is mainly used to produce protein feed. In 2018, the gap of protein feed raw material in China is about 25 million tons. It is predicted that by 2022, the gap will reach 42 million tons. Therefore, it is of great significance to develop and use other protein resources. According to the current situation, soybean meal is in short supply, while cottonseed utilization is still not very high. In 2018, the market price of soybean meal was 2767 yuan / ton, and the market price of cottonseed oil residue (COR) was only 2305 yuan / ton. COR has great potential as an ideal and new protein adhesive material.

China produces 8-10 million tons of cottonseed annually. The cottonseed contains about 50-55\% cottonseed, 30-35\% oil and $35-38 \%$ protein. COR is a by-product of cottonseed extracted by prepressing or direct solvent extraction. Its protein content can reach $50 \%$ and higher, but it has not been effectively utilized. The main reason is that it contains gossypol, which will affect the growth of animals after consumption. Therefore, the amount of COR added to the feed is only $3 \%-4 \%$. In many places, COR is returned to the field as fertilizer.

The objective of this study was to investigate the feasibility of using COR as adhesive for making wood composite panels. The adhesives were synthesized from cotton seed meal, maleic anhydride, and urea. The adhesives were then analyzed by Fourier transform infrared (FTIR) and Thermogravimetric (TG), and tested as plywood binders. The study results could provide a theoretical basis and scientific guidance for the appropriate processing method and application technology development of COR.

\section{Materials and Methods}

\subsection{Preparation of COR Adhesive}

COR was obtained from a local farm. The contents of protein, acid detergent fiber, acid detergent lignin, and neutral detergent fiber in COR are $71.8 \%, 10.1 \%, 8.9 \%$, and $0.8 \%$ of dry matter, respectively. The viscosity of COR with $15 \%$ solid content was $25 \mathrm{mPa} \cdot \mathrm{s}$. The COR was stored in a sealed glass container at room temperature $\left(22^{\circ} \mathrm{C}\right)$ before use. Maleic anhydride, urea, and sodium hydroxide were obtained from Sinopharm Group Co. Ltd, Beijing.

The synthesis procedure of COR adhesive was as following: The COR and appropriate amount of water were added into a three-neck flask. Sodium hydroxide solution of $30 \%$ concentration was used to adjust the $\mathrm{pH}$ of the mixture to 11 . The reaction mixture was stirred at $80^{\circ} \mathrm{C}$ for $20 \mathrm{~min}$. Then, the urea solution with different concentrations $(1 \mathrm{~mol} / \mathrm{L}$, $2 \mathrm{~mol} / \mathrm{L}$, and $3 \mathrm{~mol} / \mathrm{L}$ ) was added. The $\mathrm{pH}$ of the reaction mixture was adjusted to 11 and the reaction mixture was stirred at $80^{\circ} \mathrm{C}$ for $20 \mathrm{~min}$. The maleic anhydride with different contents $(3 \%, 6 \%$, and $9 \%)$ was then added. The $\mathrm{pH}$ of the reaction mixture was adjusted to 11 and the reaction mixture was stirred at different temperatures $\left(50^{\circ} \mathrm{C}, 60^{\circ} \mathrm{C}\right.$, and $70^{\circ} \mathrm{C}$ ) for $60 \mathrm{~min}$. After that, the $\mathrm{pH}$ of the reaction mixture was adjusted to $7-8$ and the obtained COR adhesive was stored in a container at room temperature.

Orthogonal experimental design was used to perform the study. Three experimental factors are urea concentration, maleic anhydride content, and reaction temperature (Table 1). Urea concentration has three levels: $1 \mathrm{~mol} / \mathrm{L}, 2 \mathrm{~mol} / \mathrm{L}$, and $3 \mathrm{~mol} / \mathrm{L}$; maleic anhydride content has three levels: $3 \%, 6 \%$, and $9 \%$; reaction temperature has also three levels: $50^{\circ} \mathrm{C}$, $60^{\circ} \mathrm{C}$, and $70^{\circ} \mathrm{C}$. Therefore, to simplify the experiment, the total number of experiment is nine.

Table 1. Experimental factors of adhesive.

\begin{tabular}{ll}
\hline Urea concentration & $1 \mathrm{~mol} / \mathrm{L}, 2 \mathrm{~mol} / \mathrm{L}, 3 \mathrm{~mol} / \mathrm{L}$ \\
Maleic anhydride content & $3 \%, 6 \%, 9 \%$ \\
Reaction temperature & $50^{\circ} \mathrm{C}, 60^{\circ} \mathrm{C}, 70^{\circ} \mathrm{C}$ \\
\hline
\end{tabular}

\subsection{Adhesive Properties Evaluation}

\subsubsection{General Properties}

Viscosities of the adhesives were measured at $25^{\circ} \mathrm{C}$ in accordance with Chinese National Standard GB/T 14074-2017 with a rotational Brookfield DVS+ viscometer (Brookfield Engineering Laboratories. Inc., MA). Three replicas were performed for each test.

Solid content of the adhesives was measured in accordance with Chinese National Standard GB/T 14074-2017. Three replicas were performed for each test.

Gel time of the adhesives was also measured in accordance with Chinese National Standard GB/T 14074-2017. Three replicas were performed for each test.

\subsubsection{Fourier Transform Infrared Spectroscopy}

FTIR analysis was conducted using a Bruker Tensor II spectrophotometer (Bruker Optik GmbH. Ettlingen). The liquid samples of the COR adhesives were located on the stage of the spectrophotometer. FTIR spectra of a total of 32 scans for each sample from 4000 to $600 \mathrm{~cm}^{-1}$ wavenumber were recorded.

\subsubsection{Thermogravimetric Analysis}

TG analysis was carried out with a TA Q50 analyzer (TA Instruments, DE). All the adhesive samples were cured at $120^{\circ} \mathrm{C}$ in a convective drying oven until the weights were constant. Specimens were placed in alumina crucibles, with an empty alumina crucible used as a reference. Specimens were heated from room temperature to $600^{\circ} \mathrm{C}$ at a heating rate of $10^{\circ} \mathrm{C} / \mathrm{min}$. The flow rate of nitrogen purge gas was 20 $\mathrm{mL} / \mathrm{min}$.

\subsection{Panel Manufacturing}

Plywood manufacturing parameters were shown in Table 2. Poplar veneers with moisture content of $8-10 \%$ and thickness of 1.6-1.7 mm were cut for plywood manufacturing. The plywood with dimensions of $250 \mathrm{~mm} \times 250 \mathrm{~mm}$ was manufactured using a laboratory hot press. The adhesive application rate was $300 \mathrm{~g} / \mathrm{m}^{2}$ (double glue line). The adhesives were applied uniformly on both sides of the middle 
veneer. The hot press time, temperature, and pressure were 5.5 minutes, $125^{\circ} \mathrm{C}$, and $1.0-1.1 \mathrm{MPa}$, respectively. Two panels were made for each adhesive formulation. After pressing, the plywood panels were conditioned at room temperature and 60 percent relative humidity for 5 days.

Table 2. Plywood manufacturing parameters.

\begin{tabular}{ll}
\hline Adhesive application rate $\left(\mathrm{g} / \mathrm{m}^{2}\right)$ & 300 \\
Moisture content of veneers $(\%)$ & $8-10$ \\
Hot press temperature $\left({ }^{\circ} \mathrm{C}\right)$ & 125 \\
Hot press time $(\mathrm{min})$ & 5.5 \\
Hot press pressure $(\mathrm{MPa})$ & 1.1 \\
\hline
\end{tabular}

\subsection{Measurement of the Bonding Strength}

The bonding strength was measured according to Chinese National Standard GB/T 17657-2013. Six specimens with dimensions of $100 \mathrm{~mm}$ by $25 \mathrm{~mm}$ were cut from each panel to make a total of twelve specimens for each adhesive formulation. Before the testing of the wet strength, specimens were immersed in water at $63^{\circ} \mathrm{C}$ for $3 \mathrm{~h}$ and tested by lap shear strength in a CMT 4104 universal testing machine (MTS System Corporation, MN). The wood failure percentage was identified and recorded.

\section{Results and Discussion}

\subsection{The General Properties of COR Adhesive}

The general properties of the COR adhesives were shown in Table 3. The solid content is a basic physical parameter in the performance test of adhesive. The solid content of the adhesive will affect the bonding performance. If the solid content of the adhesive is too low, it means that the water content is too high. In the process of hot pressing, the water in the adhesive will be heated to generate steam. The more water was added, the more steam would be generated and released, the bonding performance would be affected. According to the test results, the solid contents of cottonseed adhesives were still very low. When urea concentration of $1 \mathrm{~mol} / \mathrm{L}$ was used, the solid contents of adhesives were even less than $30 \%$. When the reaction temperature increased, the solid contents also increased. The higher solid content could reduce the moisture content in the adhesive. This could bring less water to the veneers which would help reduce the hot pressing time of plywood and improve the hot pressing efficiency [14].

Table 3. General properties of adhesives.

\begin{tabular}{|c|c|c|c|c|c|}
\hline $\begin{array}{l}\text { Urea concentration } \\
(\mathrm{mol} / \mathrm{L})\end{array}$ & $\begin{array}{l}\text { Maleic anhydride content } \\
(\%)\end{array}$ & $\begin{array}{l}\text { Reaction temperature } \\
\left({ }^{\circ} \mathrm{C}\right)\end{array}$ & Solid content (\%) & $\begin{array}{l}\text { Viscosity } \\
(\mathrm{mPa} \cdot \mathbf{s})\end{array}$ & Gel time (s) \\
\hline 1 & 3 & 50 & 25.21 & 2543 & 245 \\
\hline 1 & 6 & 60 & 26.11 & 2856 & 253 \\
\hline 2 & 3 & 70 & 33.01 & 3014 & 265 \\
\hline 2 & 6 & 60 & 30.5 & 2754 & 214 \\
\hline 2 & 9 & 50 & 28.97 & 3652 & 200 \\
\hline 3 & 6 & 50 & 31.53 & 3340 & 245 \\
\hline 3 & 9 & 60 & 34.99 & 3860 & 235 \\
\hline
\end{tabular}

The viscosities of the adhesives were in a short range, from 2543 to $3860 \mathrm{mPa} \cdot \mathrm{s}$. Within this range, the adhesives could be easily applied to the veneer surface and obtain a uniform glue line, which would help improve the bonding strength. The gel times of the adhesives were from 198 to $265 \mathrm{~s}$. These gel times were relatively short compared with those of soybean protein adhesives reported before. Gel time is also an important property for the adhesive. Shorter gel time usually means higher hot pressing efficiency.

\subsection{FTIR Analysis}

Figure 1 is the infrared spectrum comparison of unmodified, urea modified and maleic anhydride/urea modified COR adhesives. The absorption peaks of $3428 \mathrm{~cm}^{-1}$ and $3333 \mathrm{~cm}^{-1}$ were $\mathrm{N}-\mathrm{H}$ and $\mathrm{O}-\mathrm{H}$ stretching vibration, $1674 \mathrm{~cm}^{-1}$ was amide I region $\mathrm{C}=\mathrm{O}$ stretching vibration, $1594 \mathrm{~cm}^{-1}$ was amide II region $\mathrm{N}-\mathrm{H}$ bending vibration, $1150 \mathrm{~cm}^{-1}$ was amide III region $\mathrm{C}-\mathrm{N}$ stretching vibration [15]. Compared with the unmodified COR adhesive and the urea modified COR adhesive, the maleic anhydride/urea modified COR adhesive has a new small peak at $2216 \mathrm{~cm}^{-1}$, which might be due to the stretching vibration caused by the reaction of cottonseed protein molecules and maleic anhydride. The cottonseed protein molecules could react with maleic anhydride to form a new structure with good stability. Therefore, the adhesive prepared is conducive to the improvement of the bonding performance.

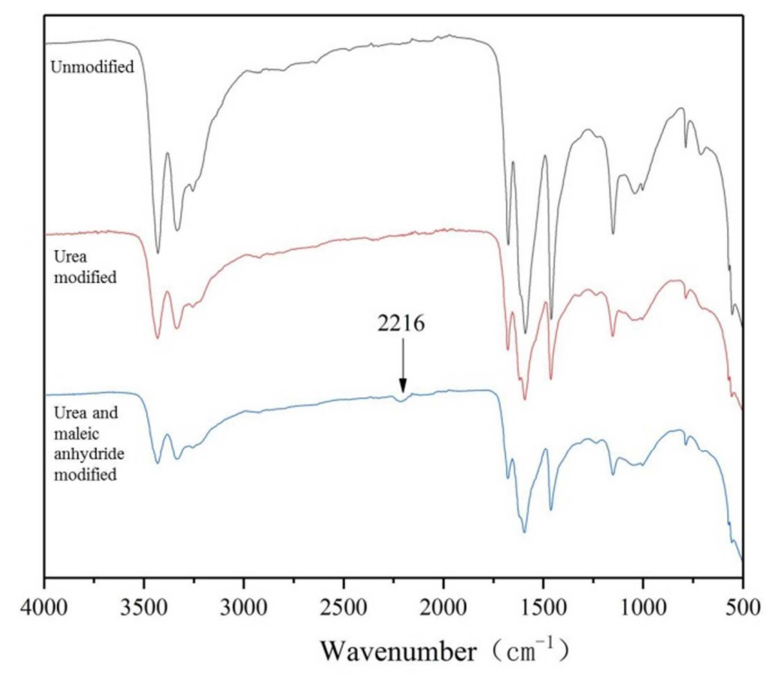

Figure 1. FTIR spectrum of COR adhesives. 


\subsection{TG Analysis}

The TG curves of unmodified, urea modified and maleic anhydride/urea modified adhesives are shown in Figure 2. It can be seen that the thermal decomposition process of the three adhesives after curing could be divided into four stages (stages I, II, III, and IV): the first stage is from $40^{\circ} \mathrm{C}$ to $130^{\circ} \mathrm{C}$, the weight loss of the three adhesives should be the water loss in the adhesive samples, and the weight loss of the maleic anhydride/urea modified adhesive is the smallest in the first stage.

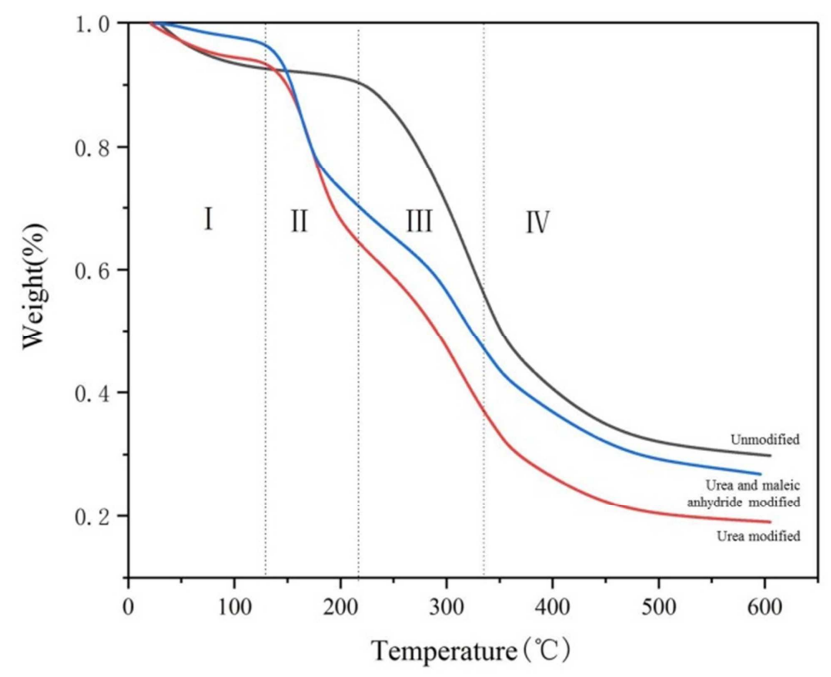

Figure 2. TG curves of COR adhesives.

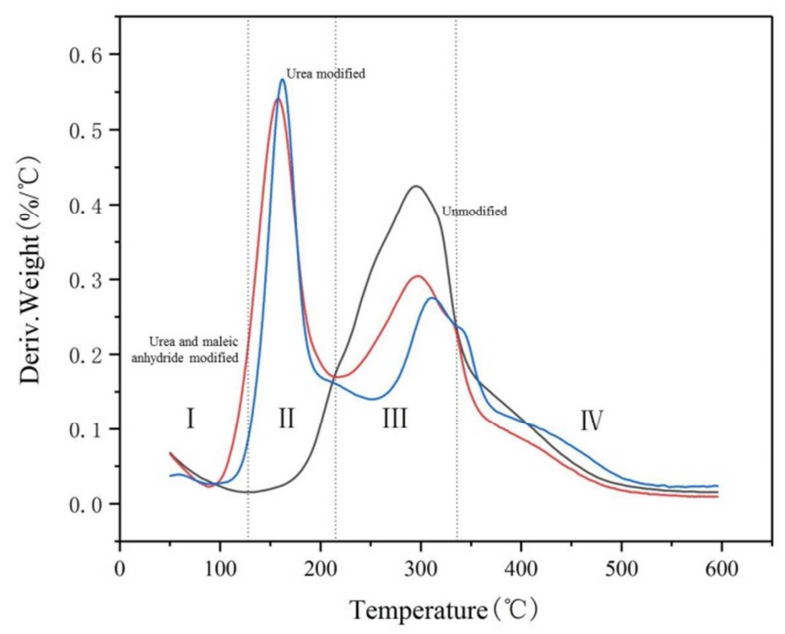

Figure 3. DTG curves of COR adhesives.

The second stage is from $130^{\circ} \mathrm{C}$ to $220^{\circ} \mathrm{C}$, during which the weight loss of unmodified COR adhesive is the smallest. The decomposition rate of urea modified adhesive is faster than that of maleic anhydride/urea modified adhesive. At the end of the second stage, the weight loss of urea modified adhesive is about $40 \%$, indicating that only using urea to modify adhesive would reduce the stability and result in no improvement of water resistance. The weight loss of the two modified adhesives might be caused by the addition of urea, which could destroy the composition of cottonseed protein and break down the macromolecular protein into protein with smaller molecules. Under the condition of high temperature, the micromolecule protein was degraded. It could be seen from the DTG curves (Figure 3) that the peak temperature $\left(162^{\circ} \mathrm{C}\right)$ of the adhesive with maleic anhydride and urea added in the second stage is higher than that of the adhesive with only urea added $\left(159^{\circ} \mathrm{C}\right)$.

The third stage is from $220^{\circ} \mathrm{C}$ to $335^{\circ} \mathrm{C}$. The weight loss in this stage could be caused by the breakdown of cottonseed protein skeleton structure. At this stage, the skeleton structure of cottonseed protein is completely decomposed, releasing $\mathrm{CO}, \mathrm{CO}_{2}, \mathrm{NH}_{3}$ and other gases resulting in weight loss. The DTG curve showed that the peak value of maleic anhydride/urea modified adhesive increased significantly from $297^{\circ} \mathrm{C}$ to $313^{\circ} \mathrm{C}$, which indicated that the thermal stability of the cross-linked modified adhesive was better than the other two adhesives.

The fourth stage is from $335^{\circ} \mathrm{C}$ to $600^{\circ} \mathrm{C}$, and the weight loss is caused by the decomposition of the structure formed by the reaction of cottonseed protein and maleic anhydride. The addition of urea expanded the structure of cottonseed protein, and the exposed $-\mathrm{NH}_{2},-\mathrm{COOH}$ and other active groups reacted with maleic anhydride, resulting in a stable new structure to improve the water resistance of the adhesive.

\subsection{Bonding Strength Measurement}

The adhesive strength is an important index to evaluate the adhesive performance. According to the national standard for class II plywood for indoor use, the wet adhesive strength after $63^{\circ} \mathrm{C}$ water treatment should be no less than $0.7 \mathrm{MPa}$. According to the data of wet adhesive strength in Table 4, the result of reaction temperature affected the most during the preparation of adhesive, which indicated that reaction temperature had an primary influence on wet shear strength and should be the main factor.

According to the range $\mathrm{R}$ : reaction temperature $\mathrm{R} 3=$ $0.458>$ maleic anhydride content $\mathrm{R} 2=0.281>$ urea concentration $\mathrm{R} 1=0.229$, so the primary and secondary order of influence of each factor is: reaction temperature $>$ maleic anhydride content $>$ urea concentration. It could be seen from this result that the reaction temperature has the greatest influence on the wet shear strength of the prepared adhesive, while the urea concentration has the least.

Table 4. Bonding strength of adhesives.

\begin{tabular}{lllll}
\hline Urea concentration $(\mathbf{m o l} / \mathbf{L})$ & Maleic anhydride content $(\%)$ & Reaction temperature $\left({ }^{\circ} \mathbf{C}\right)$ & Bonding strength (MPa) & Wood failure $(\%)$ \\
\hline 1 & 3 & 50 & 0.758 & 100 \\
1 & 6 & 60 & 1.151 & 100 \\
1 & 9 & 70 & 0.860 & 90 \\
2 & 3 & 70 & 0.946 & 80 \\
\hline
\end{tabular}




\begin{tabular}{lllll}
\hline Urea concentration $(\mathbf{m o l} / \mathbf{L})$ & Maleic anhydride content $(\%)$ & Reaction temperature $\left({ }^{\circ} \mathbf{C}\right)$ & Bonding strength (MPa) & Wood failure $(\%)$ \\
\hline 2 & 6 & 60 & 0.912 & 100 \\
2 & 9 & 50 & 0.878 & 90 \\
3 & 3 & 70 & 1.203 & 100 \\
3 & 6 & 50 & 0 & 50 \\
3 & 9 & 60 & 0.763 & 100 \\
T1 & 2.769 & 2.907 & 1.636 & $\mathrm{~T}=7.740$ \\
T2 & 2.736 & 2.063 & 2.826 & \\
T3 & 2.501 & 3.009 & \\
k1 & 2.081 & 0.969 & 0.545 & \\
k2 & 0.923 & 0.688 & 0.942 & \\
k3 & 0.912 & 0.834 & 1.003 & \\
R & 0.694 & 0.281 & 0.458 & \\
\hline
\end{tabular}

Table 5. Analysis of variance.

\begin{tabular}{llllll}
\hline Factors & Class III sum of square & Degree of freedom & Mean square & F & Significance \\
\hline Maleic anhydride & 0.156 & 2 & 0.078 & 0.521 & 0.657 \\
Temperature & 0.407 & 2 & 0.204 & 1.362 & 0.423 \\
Urea & 0.137 & 2 & 0.069 & 0.459 & 0.685 \\
Error & 0.299 & 2 & 0.150 & & \\
Total & 7.166 & 9 & & \\
\hline
\end{tabular}

It could be seen from Table 5 that considering the wet shear strength of the prepared adhesive as the index, the best synthesis parameters were that: the urea concentration was 2 mol / L, the maleic anhydride content was $6 \%$, and the reaction temperature was $70^{\circ} \mathrm{C}$, the wet shear strength of the prepared adhesive was the highest. According to the analysis of variance, the influence of the three factors on the adhesive strength of the prepared COR adhesive was not significant.

According to the data in Table 4, the plywood bonded by adhesive prepared under the conditions of urea concentration of $3 \mathrm{~mol} / \mathrm{L}$, maleic anhydride content of $6 \%$, and reaction temperature of $50^{\circ} \mathrm{C}$, was completely failed during the $63^{\circ} \mathrm{C}$ water treatment. The reason might be that the chain structure of cottonseed protein was not fully developed at low temperature and the urea concentration was also too high. The excessive urea was not involved in the reaction and stayed freely in the adhesive. Therefore, the adhesive strength was reduced.

\section{Conclusions}

In this study, bio-based adhesives were synthesized from COR, maleic anhydride, and urea. The obtained adhesives were then analyzed by FTIR and TG, and tested as plywood binders. The results indicated that the optimal synthesis conditions of the modified COR adhesive were: the urea concentration was $2 \mathrm{~mol} / \mathrm{L}$, the maleic anhydride content was $6 \%$, and the reaction temperature was $70^{\circ} \mathrm{C}$. Infrared spectrum revealed the principle of maleic anhydride/urea modification to improve the bonding strength, that is, after adding maleic anhydride, a new characteristic peak appeared at $2216 \mathrm{~cm}^{-1}$, which indicated that the protein in COR reacted with maleic anhydride to form a stable new structure, which improved the water resistance of the adhesive. The TG curve of maleic anhydride/urea modified COR adhesive showed that the peak value of the adhesive shifted back in the second and third stages, which indicated that the modified adhesive had better thermal stability and improved water resistance.
In conclusion, the study results could provide a theoretical basis and scientific guidance for the appropriate processing method and application technology development of COR.

Author Contributions: The Manuscript was written through contributions of all authors. All authors have given approval to the final version of the manuscript. Xiaosheng Liu and Huidong Su contributed equally and should be considered as co-first authors.

\section{Conflicts of Interest}

The authors declare that they have no competing interests.

\section{Acknowledgements}

The authors are grateful for the supports of the Agricultural Science and Technology Fund Project of Shandong Province (Forestry Science and Technology Innovation) (Project No. 2019LY008), Shandong Province Student Innovation and Entrepreneurship Training Program (Project No. S201910434130S), and Shandong Agricultural University Student Innovation and Entrepreneurship Training Program (Project No. XJZD2019018).

\section{References}

[1] China National Forest Products Industry Association, China Wood Based Panel Industry Report. China Forestry Publishing House, Beijing, 2019.

[2] A. Mao, E. B. Hassan, and M. G. Kim, Investigation of low mole ratio UF and UMF resins aimed at lowering the formaldehyde emission potential of wood composite boards. BioResources, 8 (2), 2453-2469, 2013.

[3] A. Mao, E. B. Hassan, and M. G. Kim, Low mole ratio UF and UMF resins entailing uron-type methylene-ether groups and their low formaldehyde emission potentials. BioResources, 8 (2), 2470-2486, 2013. 
[4] A. Mao, E. B. Hassan, and M. G. Kim, Low mole ratio urea-melamine-formaldehyde resins entailing increased methylene-ether group contents and their formaldehyde emission potentials of wood composite boards. BioResources, 8 (3), 4659-4675, 2013.

[5] A. Mao, E. B. Hassan, and M. G. Kim, The effects of adding melamine at different resin synthesis points of low mole ratio urea-melamine-formaldehyde (UMF) resins. BioResources, 8 (4), 5733-5748, 2013.

[6] X. Li, J. Luo, J. Li, Q. Gao. Effects of diatomite inorganic fillers on the properties of a melamine-urea-formaldehyde resin. Journal of Applied Polymer Science, 133 (41): 44095-44103, 2016.

[7] Y. F. Pang, W. T. Xu, Q. Li, C. Li, and A. Mao, Research progress of bio-based wood adhesives. China Forest Products Industry, 45 (4), 3-7, 2018.

[8] A. Mao, R. Shmulky, Q. Li, and H. Wan, Recycling polyurethane materials A comparison of polyol from glycolysis with micronized polyurethane powder in particleboard applications. BioResources, 9 (3), 4253-4265, 2014.

[9] A. Mao, W. Xu, E. Xi, Q. Li, and H. Wan, Evaluation of phenol-formaldehyde resins modified and blended with pyrolysis bio-oil for plywood. Forest Products Journal, 68 (2), 113-119, 2018.
[10] Q. Li. M. Li, C. Chen, G. Cao, A. Mao, and H. Wan, Adhesives from polymeric methylene diphenyl diisocyanate resin and recycled polyols for plywood. Forest Products Journal, 67 (3/4), 275-282, 2017.

[11] P. Qu, H. Huang, G. Wu, E. Sun, and Z. Chang. Effects of hydrolysis degree of soy protein isolate on the structure and performance of hydrolyzed soy protein isolate/urea/formaldehyde copolymer resin. Journal of Applied Polymer Science, 132 (7): 41469-41477, 2015.

[12] P. Qu, H. Huang, G. Wu, E. Sun, and Z. Chang. The effect of hydrolyzed soy protein isolate on the structure and biodegradability of urea-formaldehyde adhesives. Journal of Adhesion Science and Technology, 29 (6): 502-517, 2015.

[13] L. C, Y. Zhang, and X. N. Li. A high-performance bio-adhesive derived from soy protein isolate and condensed tannins. RSC Advances, 7 (34): 21226-21233, 2017.

[14] P. Wei, X. Rao, J. Yang, Y. Guo, H. Chen, Y. Zhang, S. Chen, $\mathrm{X}$. Deng, and $\mathrm{X}$. Wang, Hot pressing of wood-based composites: a review. Forest Products Journal, 66 (7/8): 419-427, 2016.

[15] Y. Li, M. Zhang, Y. Zhang, Q. Gao, A. Mao, and J. Li, Effects of different denaturants on properties and performance of soy protein-based adhesive. Polymers, 11, 1262-1275, 2019. 